\title{
Etiquetagem e folksonomia: o usuário e sua motivação para organizar e compartilhar informação na Web 2.0
}

\section{Hercules Pimenta Santos}

\begin{abstract}
Mestre pela Faculdade de Educação da Universidade Federal de Minas Gerais (FaEUFMG). Especializando em Planejamento, Implementação e Gestão da Educação à Distância pela Universidade Federal Fluminense (UFF). Professor da pós-graduação e cursos de extensão na Faculdade Milton Campos
\end{abstract}

Por meio do presente artigo, propomos conhecer e refletir sobre as recentes possibilidades de organização, representação e recuperação da informação proporcionada pelo advento da Web 2.0, tratando, aqui, especificamente, do uso da etiquetagem e da folksonomia. Buscou-se explorar representações conceituais e pretendeu-se compreender as potencialidades destes conceitos baseados em sistemas virtuais de organização e representação informacional. Assim, buscou-se refletir sobre o que leva os usuários a executar a etiquetagem dos recursos da Web e analisar como essa motivação se relaciona com o objetivo de recuperação da informação. A pesquisa apoiou-se em uma investigação teórica, com revisão de literatura sobre indexação, usuários e esquemas de representação do conhecimento na Internet. Geralmente, o que determina a utilização da etiquetagem varia entre as pessoas e os sistemas utilizados. Não é sempre que as etiquetas são atribuídas com o intuito de terem audiência e, por vezes, o que se quer é organizar os próprios dados. Entende-se, por meio deste estudo, que cada indivíduo representa um caso que requer atenção específica. Não é possível estudar, um a um, todos os grupos e perfis de usuários da informação. Faz-se necessário reunir grupos com características similares.

Palavras-chave: Organização da informação; Web 2.0; Usuários; Folksonomias. 


\section{Tagging and folksonomy: the user and his motivation to organize and share information on the Web $\mathbf{2 . 0}$}

Through this paper we propose to know and reflect on the recent possibilities of organization, representation and retrieval of information provided by the advent of Web 2.0, dealing with here, specifically, the use of tagging and folksonomy. We sought to explore conceptual representations, we sought to understand the potential of these concepts based on virtual systems of organization and representation of information. Thus, we reflect on what it takes users to perform the tagging of Web resources and analyze how that motivation relates to the purpose of information retrieval. The research was based on a theoretical investigation with review of literature on indexing, users and knowledge representation schemes on the Internet. Generally, it requires the use of labeling varies among individuals and the systems used. It's not often that the labels are assigned in order to have the hearing, sometimes what you want is to organize the data itself. It is understood, by this study, each individual case is one that requires special attention. It is not possible to study one by one, all groups and sections of information users. It is necessary to bring together groups with similar characteristics.

Keywords: Organization of information; Web 2.0; Users; Folksonomies.

Recebido em 09.10.2012 Aceito em 23.01.2013

\section{Introdução}

Por meio do presente artigo, propomos conhecer e refletir sobre as recentes possibilidades de organização, representação e recuperação da informação proporcionada pelo advento da Web 2.0, tratando, aqui, especificamente, do uso da etiquetagem e da folksonomia.

No contexto da Web 2.0, surgiram novas maneiras de se representar, organizar e recuperar informações, com base no hipertexto ${ }^{1}$,

\footnotetext{
${ }^{1}$ Nossa definição de Hipertexto surge de um corolário das considerações de vários autores (LANDOW, 1992; LÉVY, 2003; LEÃO, 2005; NEGROPONTE; TELLAROLI, 1995). Pode ser definido como uma nova concepção de leitura e escrita popularizada pelo advento da Internet. Trata-se de uma prática que depende de um suporte dinâmico, como o computador e suas funcionalidades relativas à Internet e às ferramentas que estabelecem relação direta com a leitura e a construção textual virtual. Surge uma nova forma prática de leitura,
} 
flexibilizando antigas formas de taxonomia, por meio de ideais de cooperação derivadas da noção de Web 2.0, como a folksonomia. Trata-se de uma indexação colaborativa ou democrática, que é uma abordagem centrada no usuário e está relacionada com a ideia dos usuários colaborarem com seus próprios termos para indexar determinado recurso por meio da etiquetagem (do inglês, tagging). Etiquetagem é uma forma de indexação, em que as próprias pessoas, no caso os usuários da informação, classificam documentos e objetos informacionais (BRANDT, 2009).

Explorando representações conceituais, pretendeu-se compreender as potencialidades destes conceitos baseados em sistemas virtuais de organização e representação informacional. Qual a relação entre o que vem sendo feito na $W e b$, atualmente, e a base teórica de indexação e representação do conhecimento tradicional? Buscou-se, assim, refletir teoricamente sobre o que leva os usuários a executar a etiquetagem dos recursos da Web e analisar o quanto essa motivação se relaciona com o objetivo de recuperação da informação. Para tal reflexão, nos atemos às considerações dos estudos empíricos de Brandt (2009) e Cañada (2006). A pesquisa, de forma geral, apoiou-se em uma investigação teórica, com revisão de literatura sobre indexação, usuários e esquemas de representação do conhecimento na Internet.

Assim, a partir do surgimento da possibilidade de intervenções realizadas pelos próprios usuários da Internet, as práticas de linguagem se renovam. Observa-se o surgimento de tantas quanto a nossa imaginação permite criar. As mídias digitais passaram a permitir que o usuário reinterprete, parodie e comente categorias de enunciados, como videoclipes, novelas, filmes, da mesma forma que permite a esses usuários compartilharem conteúdos de autoria própria.

Esta forma de ampliar a interação com as interfaces virtuais, por meio das quais os usuários podem interagir e produzir conteúdos, é uma das características associadas à Web 2.0. Segundo O'Reilly (2005), nesse momento, a Internet passou a estimular a chamada "arquitetura de participação", algo que não fazia parte da primeira fase dos serviços online. Considerada como a segunda geração da Internet, a Web 2.0 aparece como potencializadora das formas de publicação, compartilhamento e organização das informações online. Tim O'Reilly é o criador do termo e para ele a Web 2.0 não possui limites definidos e, sim, um "núcleo gravitacional", por ser encarada como uma plataforma na qual os próprios usuários intervêm no desenvolvimento de um processo de organização dos dados. Não se depende, aqui, de softwares offline (editores de texto, imagem ou vídeos), mas de aplicativos executados online, via programa navegador da Internet (Internet Explorer, Google Chrome, Firefox, além de vários outros).

diferenciando-se do formato linear tradicional do texto em suporte papel. Podemos considerá-lo como um processo de escrita e leitura não linear e sem hierarquias, que permite o acesso a outros textos de forma instantânea, sem a necessidade de se seguir sequências definidas. O leitor tem autonomia para elaborar o seu percurso de leitura. 
A arquitetura está baseada na cooperação, como nomeia O Reilly (2005), "the architecture of participation", com dados de origem híbrida, que permitem ser transformados. Este procedimento se traduz em uma ideia de versão "beta eterno" ${ }^{2}$, pois tudo está sempre sendo construído de forma colaborativa, no intuito de atender às necessidades momentâneas de seus usuários.

Entende-se que estes recursos se tornaram possíveis não apenas em função dos avanços tecnológicos, mas, sim, devido à construção de uma cultura de colaboração, que caracteriza algumas formas de sociabilidade desenvolvidas junto às novas tecnologias da informação e da comunicação. Trata-se de novas maneiras de produzir e disseminar informações formais ou informais. Anterior a este momento, dentro do século $X X$, os recursos para veiculação de informações restringiam-se, basicamente, aos meios de comunicação de massa como o rádio, a TV e os impressos. Por sua vez, estes foram recursos que estiveram disponíveis a um limitado número de pessoas com acesso privilegiado às suas, para aquele momento histórico, complexas estruturas técnicas de produção. Atualmente, a produção e divulgação de áudio, vídeo e textos, via Internet, exige conhecimentos e estruturas tecnológicas elementares.

Os recentes dispositivos de informação e comunicação, a partir de novos padrões de compartilhamento, preservação e disseminação da informação, beneficiam-nos, por meio de suas potencialidades. Com as redes sociais virtuais, compreendidas como um conjunto de atores conectados por relações de amizade, trabalho ou troca de informação, ampliam-se imensamente as possibilidades de interconexão entre os sujeitos na Web e permitem inúmeras complexidades à participação social. Qualquer indivíduo, com um entendimento técnico ou tecnológico mínimo, tem a possibilidade de tornar público o que pensa e produz. O desenvolvimento das tecnologias de informação e o aperfeiçoamento das interfaces gráficas virtuais permitem divulgar produções musicais, fotografias e vídeos, por exemplo, por meio do YouTube ${ }^{3}$, gratuitamente.

Para Strehl (2011), trata-se de um recurso que ultrapassaria os limites da comunicação formal do conhecimento pelos próprios autores, alcançando, assim, um estágio anterior, informal, pela reelaboração de ideias pelos próprios leitores. São informações conectadas na Web por meio de links, mas, como estes dados estão sendo organizados? Quem e como os tem representado? Quais os elementos motivadores e como estão sendo categorizados? Como os recuperamos?

\section{Etiquetagem e folksonomia}

\footnotetext{
${ }^{2}$ Versão "beta" se refere a softwares ainda em fase de desenvolvimento e testes que, posteriormente, serão considerados como versão final, ou seja, finalizado para ser distribuído.

${ }^{3}$ YouTube é uma plataforma fundada em fevereiro de 2005, que permite aos seus usuários compartilhar vídeos em formato digital. É considerado o mais popular site do tipo, possibilitando a hospedagem de variados formatos de imagem em movimento, como filmes completos, videoclipes e materiais caseiros. $\mathrm{O}$ material encontrado no YouTube pode ser compartilhado em blogs e sites pessoais, por meio de mecanismos elaborados pelos desenvolvedores do site.
} 
As bases de dados especializadas e seus precedentes, os índices e os resumos, desempenham, historicamente, um papel de extrema importância no processo de divulgação, organização e recuperação da informação. A representação das partes e dos conteúdos dos objetos informacionais permite, em meio a uma imensa gama de conteúdos e tipos de informações, identificar mídias sobre um determinado assunto do seu interesse. Anterior a estes mecanismos, dependia-se de um serviço especializado para coletar, tratar e disseminar dados para uma comunidade ou necessidade específica.

Atualmente, contamos com um grande número de usuários da informação que fazem estas mesmas tarefas de modo colaborativo, alimentando bancos de dados disponíveis virtualmente, que, segundo preconiza Strehl (2011), tão melhores ficam quanto mais pessoas os utiliza.

O termo folksonomia deriva de taxonomia. Os sistemas de representação, organização e recuperação de informações funcionam por meio da taxonomia, organizando as informações em classes e subclasses de um vocabulário (ver Figura 1). Entre outras características, este procedimento pode limitar o usuário em sua pesquisa, na medida em que o resultado de suas buscas seja definido em função de uma determinada listagem de termos relacionados com um determinado assunto. Caso, no momento da busca, o usuário não utilize alguma palavra da listagem criada para tal assunto, sua busca não lhe trará resultados férteis. A taxonomia utiliza listagens construídas por pessoal especializado em organizar informações e não pelo próprio corpo de profissionais de cada área. Desta forma, muitas vezes, algum termo de grande importância, dentro de um campo do saber, pode ficar excluído da listagem de um vocabulário chamado "controlado" (DREYFUS, 2001). 
Figura 1 - Exemplo de taxonomia dos departamentos do site Submarino.com. $\mathrm{br}^{4}$

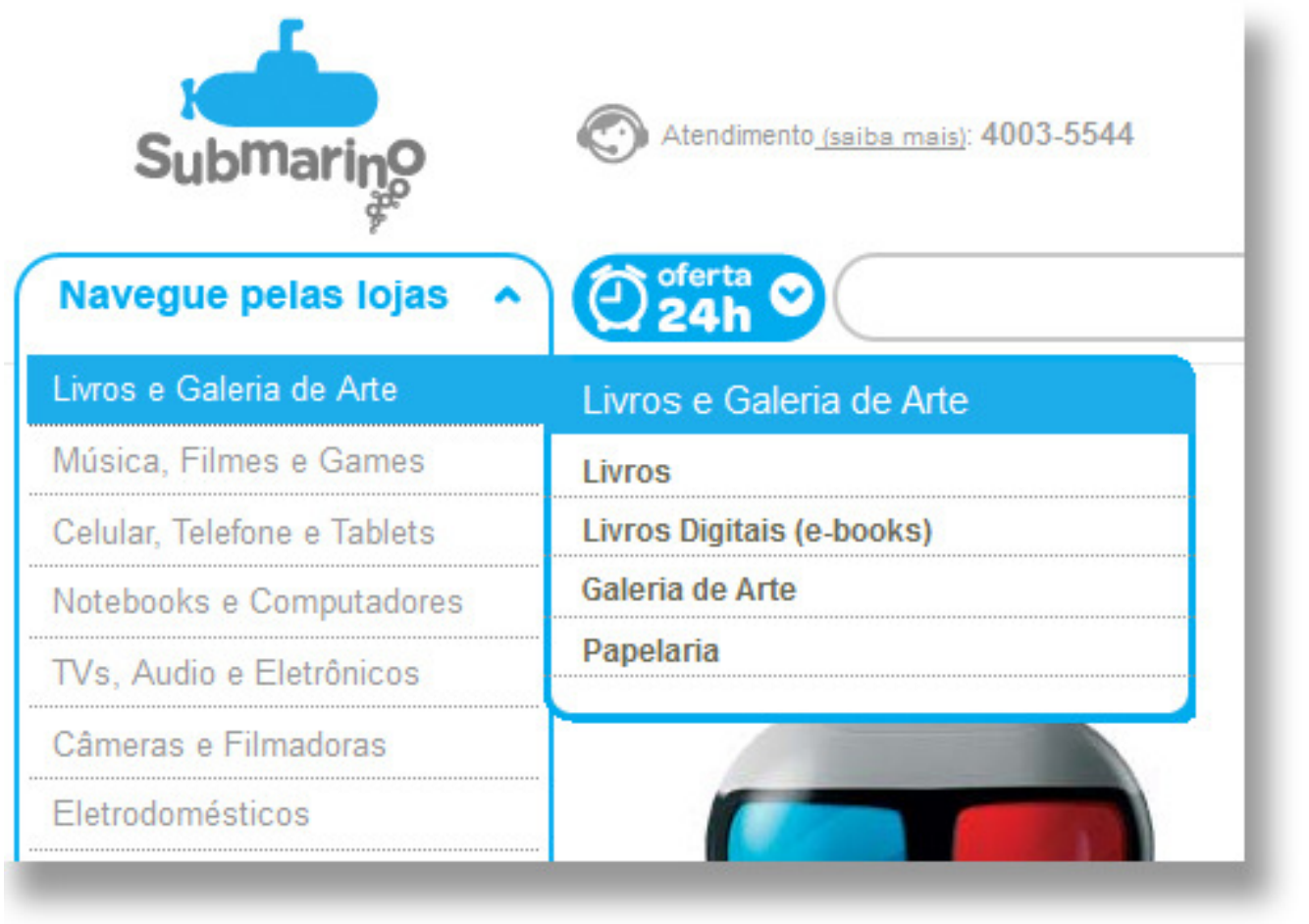

Diferente das taxonomias, as folksonomias são sistemas de classificação distribuídos, criados por usuários individuais (GUY; TONKIN, 2006). Assim, a folksonomia, como seu nome sugere ${ }^{5}$, é uma taxonomia elaborada pelo povo (ver Figura 2). A etiquetagem e a folksonomia destacam-se de formas mais ou menos intensas, dependendo do site e do objeto informacional, o que é justificado pelo objetivo de cada serviço virtual que emprega este recurso

Figura 2 - Folksonomia: exemplo de etiquetas/etiquetagem (tags/tagging) atribuída pelos próprios usuários no serviço de social bookmarks ${ }^{6}$

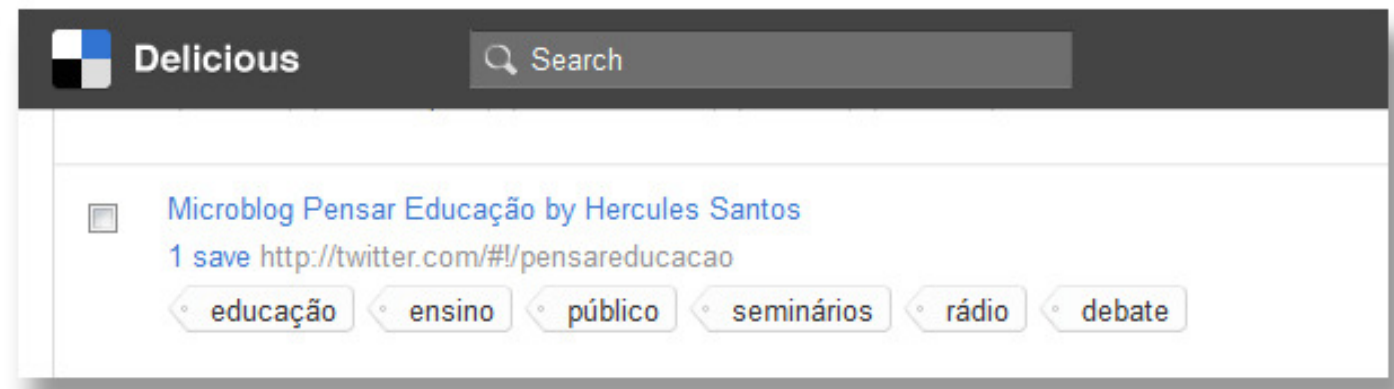

Vander Wal (2005) define etiquetagem como uma maneira não hierárquica de organização informacional. A informação é localizada por

\footnotetext{
${ }^{4}$ Disponível em: www.submarino.com.br. Acesso em: 23 maio 2013.

5 O termo "folksonomia" foi cunhado por Thomas Vander Wal. É a junção da palavra inglesa folks, determinando pessoas, e taxonomia, que é a ciência de classificar, formando algo literal como "classificação do povo".

${ }^{6}$ Disponível em: https://delicious.com. Acesso em: 23 maio 2013.
} 
meio de correlações associativas e inferências. Para o autor, as hierarquias foram uma maneira eficiente de organizar a informação antes do surgimento da computação.

Morrison (2008) considera que, em uma definição bem estrita, folksonomia deve incluir apenas os marcadores. Deve excluir qualquer sistema que apresente títulos e descrições documentais, sistemas de classificação e recomendação. Para este autor, uma determinada folksonomia pode assemelhar-se a uma rede de conexões sociais entre usuários, outra pode ignorá-la. A definição preferida de Morrison inclui aspectos como a coleção de termos constituída por contribuições de usuários; dos usuários participarem da classificação e da avaliação, além de; a adição, classificação ou a avaliação dos itens a ser realizada, por intermédio de uma rede social.

No entanto, uma divergência significativa está em que, no sistema baseado em folksonomias, não temos uma única diretriz orientando a representação dos objetos informacionais. Esta é uma tarefa distribuída entre os inúmeros usuários de um serviço, oriunda de uma política global de indexação (STREHL, 2011). Pois, nas folksonomias, a atribuição de marcadores está relacionada com a identificação da significação particular dos objetos para cada um dos usuários do sistema e, geralmente, não sendo representativas dos conceitos ali abordados.

Mesmo havendo semelhanças com os sistemas que utilizam uma linguagem natural (LARA, 2009), autorizando a existência de formas variadas de representação para um único conceito, os recursos devem ser diferenciados por sua natureza. Seus marcadores não são resultado apenas de uma diversidade de formas de expressão permitidas pela linguagem. Provêm, também, de uma imensidão de significados que podem ser atribuídos a um mesmo documento por diferentes indivíduos provenientes de inúmeros contextos.

Assim, ao termos os próprios usuários se utilizando de ferramentas cooperativas, organizando a informação de forma que possam recuperá-la por meio de uma busca apoiada por conexões e significados, constata-se uma eventual mudança nos padrões organizacionais dos dados na Web.

Diante de tal contexto, Dreyfus (2001) vai criticar a forma como as informações são dispostas na $W e b$, entendendo que, se não houver um cuidado em limitar o que deve ser etiquetado com o que, as atribuições podem se proliferar desordenadamente não existindo hierarquias e tudo seria ligado a tudo no mesmo nível.

\section{0 usuário e os fatores motivadores para a folksonomia}

O estudo do perfil e das necessidades dos agentes consumidores da informação, com suas características cognitivas e culturais, é, para a ciência da informação, uma tarefa dos estudos sobre usuários. Busca-se uma compreensão das características destes sujeitos quanto às suas motivações, recuperação e uso da informação, interagindo, assim, com diversos sistemas de informação. 
A importância do usuário cresce na abertura à sua participação por meio de comentários ou pela possibilidade de intervir em processos colaborativos que a Web 2.0 o proporcionou. Passamos, pode-se dizer assim, a uma era de customização das interfaces e das plataformas de interação pelo próprio usuário.

Alguns estudos que têm como objeto os usuários da informação, focam em sua motivação. Motivação é descrita como ativadora ou despertadora de comportamentos, geralmente, dirigidos para a satisfação de sua necessidade instigadora: "motivo ou motivação, refere-se a um estado interno que pode resultar de uma necessidade. É descrito como ativador ou despertador [...] de comportamento" (DAVIDOFF, 2005, p. 32).

Uma questão social que os sistemas suscitam refere-se à motivação pela qual as pessoas estão aderindo a este tipo de serviço de classificação da informação na Web, a folksonomia. Usuários são motivados por necessidades pessoais, mas, também, por interesses sociais. Para o usuário que quer apenas organizar os próprios dados, este está atribuindo para o seu próprio benefício de organização informacional, uma etiqueta, termo que deriva da palavra tag da língua inglesa. Outros apreciam os aspectos sociais da prática. Também, há os que não desenvolvem o mínimo interesse em compartilhar suas etiquetas com outras pessoas (MARLOW et. al, 2006). Assim, a motivação é classificada em organizacional ou social.

Fatores motivacionais influenciam nos atos que levam ao compartilhamento de informações entre indivíduos. Estes são divididos, conforme Ipe (2003), em internos e externos. Fatores internos estão ligados a sentimentos de poder, ao conhecimento e à reciprocidade que vão resultar do compartilhamento. Fatores externos se referem ao relacionamento com o receptor e com a recompensa obtida em compartilhar esta forma de organização informacional, seja qual for a natureza desta recompensa. Quanto à existência de uma reciprocidade no ato de compartilhar, Dyer e Nobeoka (2000) consideram que esta seria apresentada de duas maneiras: direta, ocorrendo quando dois usuários exercem, concomitantemente, os papéis de emissores e receptores da informação e indireta, na qual surge um terceiro indivíduo que contribui sem a expectativa de receber algo em troca. Os autores destacam que, em relação ao terceiro usuário, enquanto ele não tiver a certeza de que receberá uma compensação direta em troca da informação compartilhada, a tendência deste é a de zelar pelas informações que possui para um posterior compartilhamento.

Para Ipe (2003), dentro dos motivadores internos, o sentimento de poder é vinculado à ideia de que "conhecimento é poder", percepção que pode dificultar o compartilhamento. Ao ter ciência de que o conhecimento Ihe confere importância, a tendência do sujeito será a de acumular conhecimento. Porém, havendo sinalização de reciprocidade, passa-se a contar com uma facilidade na socialização, podendo ocorrer quando os usuários percebem que o valor que agregam depende do quanto eles compartilham os seus conhecimentos uns com os outros. 
Estas proposições, apresentadas por Ipe (2003) e Dyer e Nobeoka (2000), nos levam a pensar nos estímulos e características próprios de cada serviço online que colaborariam ou não para o surgimento dos sentimentos e percepções descritas pelos autores. Pois, segundo Cohen (1998), implícito ao ato de compartilhar informações existiria o sentimento de reciprocidade. Cohen acredita que os indivíduos só compartilham se receberem algo em troca. Além deste motivador, estaria inerente ao fator compartilhamento de informações o se sentir parte integrante de uma comunidade da qual, para se manter membro, deve-se praticar o compartilhamento entre os demais atores do processo. Diante deste quadro, pensamos quais os estímulos e características emanados de cada serviço online que colaborariam, ou não, para o surgimento dos sentimentos e percepções descritas pelos autores? Acreditamos que esta seja uma questão que merece ser trabalhada com maior profundidade em outra oportunidade.

Ipe (2003) analisa os fatores externos que influenciam na motivação para compartilhar informações sob a ótica do relacionamento entre o transmissor e o receptor da informação. O relacionamento com o receptor incluiria a confiança, o poder e o status do próprio receptor. A decisão de dar algo em troca de algo recebido estaria baseada na confiança. Havendo ausência de confiança, as práticas formais para as trocas informacionais tornar-se-iam insuficientes para 0 ato de se compartilhar dentro de um sistema.

As oportunidades também integram os fatores que influenciam no compartilhamento, identificados por Ipe (2003), podendo ser estes de natureza formal ou informal. Ele vai destacar que, como forma de facilitar o compartilhamento do conhecimento organizado e sistematizado, as oportunidades formais abrangem programas de treinamento, estruturação de grupos de trabalho e um sistema baseado em tecnologia.

Já Nowak e Sigmund (2000) acreditam no status como fator motivador. Estes salientam que o ser humano possui obsessão por reputação positiva e pelo status que venha a adquirir em uma comunidade na qual esteja inserido. Os autores acreditam que esse status pode ser um fator implícito que motiva o compartilhamento de informações, uma vez que seja visto com bons olhos pelos demais membros do sistema. Entende-se, desta forma, que a reputação a qual o indivíduo tem a possibilidade de alcançar seria também um dos fatores motivadores para o compartilhamento da sua maneira de organização informacional. Este fator também acabaria por levar esta organização a ser intensificada, por parte deste perfil psicológico de usuário, em um sistema ou serviço virtual ao qual o indivíduo esteja integrado.

\section{Motivadores constatados por Brandt e Cañada}

Desenvolver e aprimorar ferramentas que captam, não somente o conteúdo dos documentos, mas o sentido que as pessoas lhes atribuem, vão ampliar as possibilidades de recuperação das informações de um sistema (STREHL, 2011). Assim, citamos, aqui, dois estudos empíricos 
que procuram ampliar as noções sobre o usuário e a sua motivação em relação à organização da informação na Web.

Brandt (2009), apesar do seu estudo de usuários ter sido realizado em ambientes limitados e ter uma pequena quantidade de participantes, apresenta indícios de que os atores do processo participam de forma colaborativa da etiquetagem, com objetivos de organização e recuperação da informação etiquetada. A autora, analisando os serviços Delicious ${ }^{7}$ e Flickr $^{8}$, buscou avaliar o potencial da etiquetagem e da folksonomia para a organização e recuperação da informação, verificando se essa prática teria alguma validade. Sua pergunta principal foi, basicamente, qual seria a relação entre o que vem sendo feito atualmente na Web e a base teórica de indexação e representação do conhecimento, tradicionais, na Biblioteconomia e na Ciência da Informação?

Ao analisar os mesmos serviços, Delicious e Flickr, em uma perspectiva de "tagging social"9, Javier Cañada (2006) sugeriu a existência de quatro estilos bem definidos de etiquetadores, com distintas motivações na adaptação da linguagem em tais sistemas: etiquetadores egocêntricos, amigáveis, altruístas e populistas. Cañada (2006) classifica, ainda, as suas análises em benefícios sociais e motivações.

Para Cañada (2006), os etiquetadores egocêntricos trariam algum benefício social, variando entre baixo e médio. Ao utilizar palavras mais pessoais, o etiquetador egoísta acaba por gerar heterogeneidade de termos para os sistemas. Ao contrário desta prática, se um usuário começa a sistematizar a sua etiquetagem, se valendo, por exemplo, de rótulos temáticos, consequentemente ele contribui com uma uniformidade benéfica para o mesmo sistema. A motivação para o egocêntrico é alta, porém, exclusivamente a seu favor em relação à organização e futura recuperação da informação.

Os etiquetadores amigáveis apresentam benefício social alto. Apesar deste estilo de etiquetagem contribuir muito pouco para grandes grupos, ele é extremamente útil em pequenos sistemas. Aqui, os sujeitos interagem, utilizando uma linguagem de referência que tem significação muito própria do grupo de compartilhamento. A motivação pela rotulagem, neste caso, é muito alta, servindo para partilhar e para fortalecer um senso de comunidade entre o grupo.

Etiquetadores altruístas trazem benefício social muito alto, segundo Cañada (2006). Este estilo de rotulagem é o que mais contribui para

7 O Delicious é um serviço encontrado na Internet que the permite adicionar, mas, também, pesquisar, Bookmarks, ou Favoritos, sobre qualquer assunto. Trata-se de uma ferramenta de arquivamento e catalogação de sites preferidos, principalmente aqueles poucos práticos de se decorar a sua URL. Tal serviço possibilita acessá-las a qualquer momento de qualquer computador com acesso à Web. Este tipo de serviço de compartilhamento de links favoritos também é conhecido pelo termo da língua inglesa social bookmarks.

${ }^{8}$ O Flickr é um serviço da Web basicamente para hospedagem e compartilhamento de imagens fotográficas, além de outros tipos de documentos gráficos, como desenhos e ilustrações. O Flickr possibilita a seus usuários criar álbuns para alocar e disponibilizar online as suas fotografias.

9 Marlow et. al. (2006) descrevem como Tagging Social os sistemas que incorporam a folksonomia ao seu funcionamento. A prática de etiquetar um recurso seria semelhante à categorização dos bookmarks, ou seja, uma relação de sites "Favoritos", nomeado ainda por Bookmarking Social, que são as ferramentas para o armazenamento de bookmarks em serviços online, ou os tagging systems. O Delicious é um exemplo deste sistema. 
facilitar a recuperação das informações para outros usuários, por ser o mais generoso. Seus atores sociais buscam estabelecer padrões na adoção dos termos. A motivação, aqui, no entanto, é baixa. Pois, esta forma de etiquetagem é trabalhosa, tornando-se uma tarefa difícil motivar alguém a fazer um trabalho para beneficiar outras pessoas, uma vez que não existiria um retorno direto associado a esta prática.

Os etiquetadores populistas, segundo as classificações e análises de Cañada (2006), não oferecem qualquer benefício social. Rotulam os seus objetos informacionais com termos considerados os mais atraentes, buscando o objetivo de obter maior número de acessos. Para tal, usam-se etiquetas que são populares e atrativas, para a maioria das pessoas, como por exemplo: muito bom, sexo, superinteressante, top 10. A motivação, neste caso, é alta, pois, ao se recorrer a este estilo de marcação, busca-se por um objetivo direto e óbvio. Também consiste, assim entendemos, em uma tarefa fácil de realizar, o que vai contribuir muito na motivação. Porém, o trabalho de rotulagem se torna completamente inútil, quando se refere a recuperar informações de forma eficiente.

\section{Considerações finais}

A Web 2.0, com suas possibilidades colaborativas, propicia um redimensionamento permanente, por meio de uma construção coletiva, da sua rede hipertextual. As informações ganham novas formas de serem organizadas em função da folksonomia, por meio da etiquetagem, constituindo-se em links de um amplo hipertexto, uma tecnologia que permite gerar tais ligações ao mesmo tempo em que se constituirá em um produto resultante destas ligações. Além de concretizar objetivos como os de organização da informação, podem suscitar novas maneiras de organizar e recuperar dados pelos próprios usuários de forma coletiva e semântica, algo em estreito acordo com os princípios originários da coletividade do hipertexto, permitindo a busca pelas informações por meio de significados.

A relação hipertexto na $W e b 2.0$ e as folksonomias permite ao usuário a utilização de mecanismos mais flexíveis do que as taxonomias, por meio do uso de um "vocabulário descontrolado". Este vocabulário amplo se relaciona muito bem com os formatos hipertextuais, pois, além de uma organização semântica das informações, permite, também, uma organização coletiva e colaborativa da/na $W e b$, seja ela intencional ou não.

Por meio da folksonomia, é possível constituir uma rede de associações com base no significado eleito, individualmente ou por senso comum, no entanto, sem depender de um contexto de criação. O que geralmente vai determinar a utilização das etiquetas variará entre as pessoas e os sistemas utilizados. Não é sempre que as etiquetas são atribuídas com o intuito de terem audiência, ou seja, que o usuário adiciona uma etiqueta, tornando-a pública. Por vezes, o que se quer é organizar os próprios dados. 
Um fator importante, dentre outros, que influencia no compartilhamento da informação e organização do conhecimento é a motivação do usuário. Definimos a motivação como o que impulsiona o usuário a agir de determinada forma ou ter determinada atitude ou comportamento, diante de uma situação informacional. Nota-se que alguns perfis de usuários, geralmente, não compartilham informações sem uma motivação definida e, provavelmente, não o partilhariam sem saber o que poderiam obter ou perder com tal prática. Por meio desta análise, foi possível identificar alguns elementos que colaboram na motivação para uma organização informacional não formal e, consequentemente, o seu compartilhamento, como, por exemplo, a confiança, a amizade, a afinidade, a reciprocidade, o status adquirido e a doação. A ação relacionada a esses elementos tem características que são de origem interna e são construídas ao longo do tempo, por envolver valores, crenças, sentimentos e interesses em comum.

Entende-se, por meio deste estudo, que cada indivíduo representa um caso que requer atenção específica. Não é possível estudar um a um, todos os grupos e perfis de usuários da informação. Faz-se necessário reunir grupos com características similares, como usuários conhecidos, desconhecidos, individuais, coletivos, técnicos, particulares, investigadores e pesquisadores. Trata-se de uma perspectiva de classificação de usuários em grupos, com características similares, de acordo com o desempenho das suas funções sociais, algo como é proposto por Guinchat e Menou (1994) e Sanz Casado (1994)

Aponta-se a importância de novos estudos similares a este, que abordem temas que envolvem os assuntos Web 2.0 e a organização e classificação informacional, este último, também, em sua forma tradicional. Uma vez que, aparentemente, ainda não foram tratados com aprofundamento, apontado pelas ausências constatadas na discussão aqui presente. Pois, diante da reflexão teórica realizada neste trabalho, surgem algumas perguntas que demandariam um estudo mais aprofundado e a utilização de metodologias capazes de Ihes dar resposta. Sentimos a necessidade de saber, por exemplo, qual seria o impacto que essas novas práticas de representação, organização e recuperação da informação; o impacto que geram ao revisitarmos as tradicionais formas, como as taxonomias. Também, pensamos se, diante de um número tão variado de perfis de usuários gerando, se apropriando, parodiando e gerenciando informação, com certa liberdade, o quanto isto vem contribuindo para a existência de um caos informacional na $W e b$. São preocupações que nos impulsionam a buscar explicações para novos fenômenos informacionais que ajudam a compreender melhor e, por outros ângulos, os formatos já considerados tradicionais da organização e representação informacional.

\section{Referência}

BRANDT, M. B. Etiquetagem e folksonomia: uma análise sob a óptica dos processos de organização e recuperação da informação na web. $142 \mathrm{f}$. Dissertação (Mestrado em Ciências da Informação) - Universidade de 
Brasília, Faculdade de Economia, Administração, Contabilidade e Ciência da Informação, 2009.

CAÑADA, J. Tipologias y estilos en el etiquetado social. 2006. Disponível em: <http://www.terremoto.net/tipologias-y-estlos-en-el-etiquetadosocial/>. Acesso em: 29 jun. 2012.

COHEN, D. Towards a knowledge context: report on the first annual U.C. Berkeley Forum on Knowledge and the firm. California Management Review, Berkeley, v. 40, n. 3, p. 22-39, 1998.

DAVIDOFF, L. L. Introdução à psicologia. São Paulo: Pearson Makron Books, 2005.

DREYFUS, H. L. On the Internet. Londres: Routledge, 2001.

DYER, J. H.; NOBEOKA, K. Creating and managing a high performance knowledge sharing network: the Toyota case. Strategic Management Journal, v. 21, p. 345-367, 2000.

GUINCHAT, C.; MENOU, M. Usuários. In: FIGUEIREDO, N. M. Introdução geral às técnicas da informação e da documentação. Brasília: IBICT, 1994. p. 481-491.

GUY, M.; TONKIN, E. Folksonomies: tidying up tags? D-Lib Magazine, v. 2, n. 1 2006. Disponível em: <http://www.dlib.org/dlib/january06/guy/01guy.html>. Acesso em: 14 maio 2012.

IPE, M. Knowledge sharing in organizations: a conceptual framework. Human Resource Development Review, v. 2, n. 4, p. 337-359, Dec. 2003.

LANDOW, G. P. Hipertexto: la convergencia de la teoría crítica contemporánea y la tecnología. Tradução de Patrick Ducher. Barcelona: Paidós, 1992.

LARA, M. L. G. de. Linguística documentária: seleção de conceitos. 178 f. Tese (Livre-docência) - Escola de Comunicações e Artes, Universidade de São Paulo, São Paulo, 2009.

LEÃO, L. O labirinto da hipermidia: arquitetura e navegação no ciberespaço. 3. ed. São Paulo: FAPESP: Iluminuras, 2005.

LÉVY, P. O que é o virtual? Tradução de Paulo Neves. São Paulo: Editora $34,2003$.

MARLOW, C. et. al. Position paper, tagging, taxonomy, flickr, article, toread. 2006. Disponível em: <http://www.danah.org/papers/WWW2006.pdf>. Acesso em: 3 jul. 2012.

MORRISON, P. J. Tagging and searching: search retrieval effectiveness of folksonomies on the World Wide Web. Information Processing and Management, v. 44, p. 1562-1579, 2008.

NEGROPONTE, N.; TELLAROLI, S. A vida digital. 2. ed. São Paulo: Companhia das Letras, 1995. 
NOWAK, M. A.; SIGMUND, K. Enhanced: shrewd investments. Science, v. 288, n. 5467, p. 819-820, 2000.

O'REILLY, T. What is Web 2.0? 2005. Disponível em: <http://oreilly.com/web2/archive/what-is-web-20.html>. Acesso em: 26 jun. 2012.

SANZ CASADO, E. Manual de estudios de usuarios. Madrid: Pirâmide, 1994.

STREHL, L. As folksonomias entre os conceitos e os pontos de acesso: as funções de descritores, citações e marcadores nos sistemas de recuperação da informação. Perspectivas em Ciência da Informação, v.16, n. 2, p.101-114, abr./jun. 2011.

WAL, T. V. From tags to the future. 2005. Disponível em: <http://www.vanderwal.net/random/category.php?cat=153>. Acesso em: 29 jun. 2012. 